\title{
LA PROPIEDAD DE LA TIERRA EN LA MANCHA BAJA (CUENCA)
}

\author{
POR \\ MANUEL GESTEIRO ARAÚJO
}

\section{Introducción}

En este artículo nos proponemos estudiar la estructura de la propiedad de la tierra en la Mancha Baja (Cuenca) a partir de la información contenida en los Padrones de Propietarios del Catastro de Riqueza Rústica del año 1988. Hemos complementado los datos catastrales con las noticias que, sobre las explotaciones agrarias, nos proporcionan los censos agrarios y por una investigación personal en algunos pueblos y explotaciones agrícolas de esta comarca que, con mayor amplitud, hemos desarrollado en nuestra tesis doctoral.

En primer lugar realizaremos unas consideraciones sobre el medio natural y los aprovechamientos agrícolas más importantes de esta comarca y a continuación estudiaremos la estructura de la projiedad rústica. Comenzaremos con una breve exposición sobre la hisria de la propiedad agraria para centrarnos, y este es el principal ietivo del artículo, en el estudio de la propiedad actual. Delimitare; unos grandes tipos de propietarios y realizaremos un análisis nunicipios a partir del tipo de propiedad dominante en los mis-

\section{Medio natural y aprovechamiento agrario}

La Mancha Baja es una comarca establecida por el Ministerio de Agricultura en 1978; consta de 26 municipios situados en el SW de 
la provincia de Cuenca y nosotros le hemos añadido tres términos más, en su parte oriental, con lo que nos encontramos ante un espacio comarcal de 256.776 ha.

a) El medio natural.-Esta comarca se encuentra entre las estribaciones meridionales de la mesozoica sierra de Altomira, los materiales cenozoicos de la mesa manchega y el inicio de la llanura manchega con sedimientos cuaternarios.

Aproximadamente un $55 \%$ de la superficie comarcal se encuentra entre los 700-800 m de altitud. Las mayores elevaciones corresponden a los relieves calizos de la zona norte culminando en el pico de La Cruz (1.057) en la sierra de Almenara, mientras las mínimas no superan los 700, en la zona endorreica de las llanuras meridionales.

Las alineaciones tectónicas están, en líneas generales, orientadas de norte a sur y ello influye notablemente sobre la hidrografía ya que los principales cursos fluviales siguen la misma dirección, instalándose en los sinclinales y condicionando también la orientación de las lagunas y charcas. El río Záncara y su afluente el Rus y el MonrealSaona vierten sus aguas en el Guadiana, ya en plena llanura y fuera del espacio estudiado. En la zona SW, entre Mota del Cuervo y Las Pedroñeras, hay una importante zona endorreica orientada de NNW a SSE coincidiendo con la disposición de los relieves mesozoicos.

Los suelos dominantes son los pardo-calizos en las zonas de llanura, profundos y de un alto valor agrológico, mientras que, sobre las calizas mesozoicas de la sierra, son xerorendzinas que retienen poca humedad dado su carácter permeable.

$\mathrm{Su}$ clima es mediterráneo continentalizado con invierno frío. Las temperaturas medias comarcales oscilan entre 13 y $14^{\circ}$ con una amplitud de 18 a $20^{\circ}$. Los inviernos son claramente fríos ya que cinco meses tienen medias inferiores a $10^{\circ}$ y el más frío no supera los $6^{\circ}$. Según Elías y Ruiz (1981) la última helada de primavera oscila entre el 1 y el 10 de mayo, mientras que la primera de otoño se produce después del 20 de octubre aunque, en la parte más occidental, puede adelantarse a la segunda decena del mismo mes. E1 período libre de heladas es ligeramente superior a los cinco meses. Los veranos son calurosos con $24-25^{\circ}$ en julio. La mínima absoluta ha sido de $-21,5^{\circ}$ (febrero de 1944) en San Clemente y la máxima se produjo en julio de 1970 con dos días de $42^{\circ}$, mes en el que se producen con más frecuencia las olas de calor. 
Las precipitaciones anuales se sitúan en torno a los 400-500 $\mathrm{mm}$ variando con la altitud. La sequía estival es muy acusada, son importantes las precipitaciones otoñales (octubre-noviembre) pero las estaciones más lluviosas son la primavera (abril-mayo) seguida por el invierno. La ETP anual es de $750 \mathrm{~mm}$ y el déficit es $350 \mathrm{~mm}$ anuales en Las Pedroñeras.

Las aguas subterráneas tienen una gran importancia en La Mancha. En nuestra comarca, la explotación de los acuíferos es cada vez más intensa. La Mancha Baja se encuentra fundamentalmente sobre el acuífero 19 llamado «Calizas de Altomira» en la parte norte, y el 23, denominado «Mancha occidental» en la meridional. Estos acuíferos se alimentan básicamente del agua de lluvia infiltrada por los materiales neógenos y las calizas mesozoicas. La descarga se produce naturalmente a través de los manantiales y, especialmente a partir de los años 70, con los numerosos y profundos pozos para el regadío. Según el IGME (1985), en 1983 ya estaba sobreexplotado el acuífero 23, bajo los mejores suelos, del cual se dedicaba más del $90 \%$ del agua extraída a usos agrarios. El 19, bajo suelos rendziniformes, por el contrario estaba todavía muy poco explotado. Unos años de lluvias abundantes pueden contribuir a elevar el nivel freático mientras que la escasez de precipitaciones que se viene produciendo unida al aumento de la superficie regada están haciendo descender notablemente las reservas de los acuíferos.

b) Principales cultivos.-El paisaje agrario de esta comarca conquense ha experimentado unas importantes modificaciones desde los años finales de la década de los sesenta.

Era un espacio en el que predominaban los tres cultivos clásicos del secano mediterráneo. Los cereales extensivos, con claro predominio del trigo, el viñedo y, en mucha menor medida, el olivar. El regadío ocupaba un lugar bastante marginal.

Como consecuencia de los cambios en los métodos y técnicas de cultivo (reducción del barbecho ampliación del regadío, mecanización, etc.), que se produjeron desde la citada década, ha tenido lugar un importante aumento de la superficie labrada y cultivada.

Dentro del espacio ocupado por los cultivos herbáceos de secano, destacamos el hecho de que se haya mantenido la superficie cerealista, en la que la cebada gana progresivamente espacio al trigo, al tiempo que se reducen notablemente los barbechos con la introduc- 
ción del girasol y, en menor medida, de las leguminosas y los ajos. El espacio dedicado a los cultivos leñosos también se ha incrementado de forma considerable debido a la expansión del viñedo y ligeramente del olivar.

El regadio ha experimentado una importante transformación ya que los viejos pozos con norias han sido sustituidos por aspersores y pivotes. De los tradicionales huertos destinados al autoconsumo, se ha pasado a productos claramente orientados al mercado como los ajos, cebollas, maíz, etc. La superficie regada, aún siendo muy reducida en este espacio comarcal, se ha ampliado notablemente tanto en las pequeñas como grandes propiedades.

\section{Antecedentes históricos de la propiedad}

A partir de los diversos documentos que constituyen el Catastro de Ensenada hemos estimado que, a mediados del siglo xvIII, un $55 \%$ de la superficie comarcal estaba integrado por las tierras de propios, comunales y eclesiásticas, y lo restante propiedad individual de seglares.

Cuadro I

PROPIEDAD EN EL SIGLO XVIII

Propios y comunales

FuENTE: Catastro de Ensenada. Elaboración propia.

La mayor parte de la propiedad concejil tiene su origen en las concesiones realizadas a los repobladores de la comarca, bien por la Orden de Santiago, bien por el Marquesado de Villena, entre los cuales se llevó a cabo la ocupación de este territorio manchego.

$$
-648-
$$


$\mathrm{Al}$, clero pertenecía el $19 \%$ de la tierra, siendo mayor la propiedad eclesiástica en aquellos municipios en los que había conventos, como era el caso de Santa María del Campo Rus (40\% del municipio), La Alberca de Záncara, Belmonte, San Clemente, etc., con el 38, 27 y 20 \% respectivamente; o encomiendas de la Orden de Santiago como en Villaescusa de Haro y su tierra (38\%), etc.

La nobleza titulada era numéricamente muy poco importante, en su mayor parte se trataba de marqueses y condes con títulos otorgados en el siglo xviI. Entre ellos destacaban el marqués de Valdeguerrero, el más rico hacendado, la mayor casa dezmera, siguiendo a Camarero Bullón, de la comarca; el marqués de Valera, un importante propietario en varios pueblos de la provincia de Cuenca, entre los cuales se encontraba la aldea Perona, posiblemente parte de un antiguo latifundio romano; el conde de Fontanar y señor de Minaya, mayor hacendado de San Clemente y Minaya que además poseía tierras en otros municipios contiguos; el señor de Santiago de la Torre, coto redondo del mismo nombre y aldea de San Clemente, de unas 2.350 ha. En total, estos nobles controlaban unas 13.000 ha., un $5 \%$ de la superficie comarcal aproximadamente.

El grupo de los labradores ricos era mucho más numeroso. Estaba integrado por los hidalgos y dones que constituían las oligarquías locales. Eran las mayores casas dezmeras en casi todos los pueblos comarcanos. Como ejemplo de su poder económico podemos citar los casos de Villaescusa de Haro y Mota del Cuervo donde 16 vecinos hidalgos de cada pueblo, poseían el 8 y el 10\% de la tierra respectivamente, o el de Villamayor de Santiago donde 31 vecinos, hidalgos y dones, eran titulares del $16 \%$ de la superficie municipal.

Las desamortizaciones del siglo XIX, eclesiástica y civil, supusieron la venta, que hayamos podido constatar documentalmente, de unas 40.000 ha, aproximadamente un $15 \%$ de la superficie comarcal.

Entre los compradores, hubo muchos que descendían de familias que ya eran importantes propietarios en el siglo anterior e incluso mayores hacendados como los Ladrón de Guevara, Lodares, Ayala, Portillo, Mena (conde de Buenavista), Bahillo (caballero de Santiago y diputado), Chico de Guzmán (caballero de Santiago y más tarde conde de Campillo y senador), Sandoval Sandoval (marqués de Valdeguerrero y diputado) Melgarejo (título pontificio de marqués del mismo apellido) etc. lo que supuso el fortalecimiento de unos patri- 
monios familiares preexistentes además de la formación de otros nuevos tanto por la adquisición de bienes de propios como de eclesiásticos.

En los años centrales de nuestro siglo (1950-60), nos encontramos con un espacio agrario claramente minifundista en el que, sin embargo, es muy importante la gran propiedad. con menos de 10 ha. tenemos al $87 \%$ de los propietarios a los que pertenecía algo menos del $25 \%$ de la tierra catastrada. Las explotaciones agrarias mayores de 200 ha., en 1962, eran el 1,7\% y les correspondía el 41,4 \% de la superficie censada.

En la citada década, hemos contabilizado 130 fincas mayores de 50 ha., que reunían el 20,7 \% de la tierra catastrada y su dimensión media era de 374 ha. por finca. Se daba además la circunstancia de que varias de ellas eran propiedad de la misma persona o de varios miembros de una misma familia. Propiedades que ya existían en el siglo XVIII y se incrementaron en el XIX, a veces se concentraron como consecuencia de uniones familiares. Quizás el más espectacular de los casos sea el de los Martínez del Peral y los Melgarejo a quienes pertenecían 16 grandes fincas, un total de 8.486 ha. repartidas entre siete municipios comarcanos. Otro ejemplo lo constituyen los Lodares, familia de importantes propietarios que ya eran mayores hacendados en el xviII y compraron unas 1.500 ha. de propios en la desamortización de Madoz, varios miembros de la misma poseían 14 fincas repartidas entre diversos pueblos con unas 3.500 ha. de superficie total, sin que hayamos contabilizado aquellos propietarios que llevan este apellido en segundo lugar, etc.

\section{La actual distribución de la tierra}

La superficie catastrada, en 1988 , era de 253.128 ha y se distribuía entre 34.134 titulares lo que nos da una media de 7,4 ha. por propietario. Sin embargo, la tierra está muy desigualmente repartida. Nada menos que el $83,5 \%$ de las propiedades era inferior a la media comarcal y únicamente les correspondía el $24,2 \%$ de la tierra catastrada. Este porcentaje de propietarios con menos de 7,4 ha es muy similar al de aquellos que estaban exentos del pago de contribución, ya que su base imponible era menor a 12.000 pts. en el citado año.

$$
-650-
$$


En el extremo opuesto nos encontramos con muy pocos propietarios a los que podemos considerar medios y grandes, los que superan las 100 ha, que son únicamente el $1 \%$ y les pertenece nada menos que el $41 \%$ del suelo comarcal.

Claramente se aprecia la existencia de un fuerte contraste entre el abrumador número de pequeños propietarios y los pocos grandes. La consecuencia es un alto grado de concentración, como nos muestran un índice de Gini próximo a 0,8 y la existencia de 131 propietarios, sin tener en cuenta que varios de ellos lo son en más de un municipio, a los cuales pertenece el $30 \%$ de la tierra y el $22 \%$ de la base imponible comarcal.

\section{Los grandes grupos de propietarios}

Es un lugar común agrupar a los propietarios de tierras en tres grandes grupos: pequeños, medianos y grandes, estableciendo unos intervalos de superficie poseída y, menos frecuentemente, de la riqueza de la misma a través de la base imponible.

El problema que se plantea es el de definir unos umbrales que permitan separar entre sí a estos grupos de propietarios. Buscaremos una delimitación en cuanto a superficie, que sea útil para entendernos y al mismo tiempo refleje el status socioeconómico que proporciona ser dueño de una determinada cantidad de tierra.

a) La delimitación de la pequeña propiedad. Tradicionalmente se ha utilizado un criterio puramente cuantitativo para definirla: aquella que es inferior a las 10 ha, a pesar de reconocer la inviabilidad de explotaciones de este tamaño en agriculturas de secano como la de la comarca que nos ocupa. Si utilizamos como criterio la base imponible, nos encontramos que en la Mancha Baja las propiedades con base inferior a las 12.000 pts, límite a partir del cual se contribuye, corresponden a una superficie media de 5,6 ha lo que nos muestra que en este caso es un criterio no aplicable por el exiguo tamaño de la propiedad a la que afecta.

Si, de acuerdo con Mata Olmo (1987), consideramos los ingresos derivados de la explotación agrícola, la pequena propiedad sería aquella que produjera al agricultor unos ingresos, equivalentes al salario mínimo interprofesional, resultado del trabajo que el campesi- 
CuAdro II

GRANDES GRUPOS DE PROPIETARIOS POR MUNICIPIOS (\%)

\begin{tabular}{|c|c|c|c|c|}
\hline Municipios & $\begin{array}{c}\text { Pequeña } \\
(<25)\end{array}$ & $\begin{array}{c}\text { Media } \\
(25-249)\end{array}$ & $\begin{array}{c}\text { Grande } \\
(>250)\end{array}$ & $\begin{array}{c}\text { Indice } \\
\text { GINI }\end{array}$ \\
\hline Alberca de Záncara ............... & 39,7 & 44,6 & 15,7 & 0,7451 \\
\hline 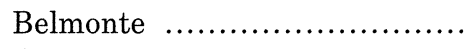 & 36,0 & 34,7 & 29,3 & 0,8007 \\
\hline Carrascosa de Haro ............... & 26,0 & 24,3 & 49,7 & 0,3242 \\
\hline Casas de Benítez ................. & 32,2 & 45,4 & 22,4 & 0,8124 \\
\hline Casas de Fernando Alonso ....... & 64,4 & 35,6 & - & 0,7088 \\
\hline Casas de Guijarro ................. & 89,6 & 10,4 & - & 06610 \\
\hline Casas de Haro .................... & 42,8 & 29,4 & 27,8 & 0,8044 \\
\hline Casas de los Pinos ................ & 50,5 & 23,6 & 25,9 & 0,7594 \\
\hline Fuentelespino de Haro ........... & 34,9 & 51,1 & 14,0 & 0,6250 \\
\hline Los Hinojosos ................... & 35,1 & 30,7 & 44,2 & 0,8028 \\
\hline Hontanaya $. . . \ldots \ldots \ldots \ldots \ldots \ldots . . . . . . .$. & 25,8 & 28,9 & 45,3 & 0,8306 \\
\hline Las Mesas .......................... & 43,7 & 27,2 & 24,1 & 0,7739 \\
\hline Monreal ........................... & 36,0 & 55,3 & 8,7 & 0,7220 \\
\hline Mota del Cuervo .................. & 44,7 & 34,7 & 20,6 & 0,7037 \\
\hline Osa de la Vega ................... & 27,9 & 60,4 & 11,7 & 0,8081 \\
\hline El Pedernoso ....................... & 27,4 & 36,1 & 36,5 & 0,8376 \\
\hline Las Pedroñeras .................. & 31,9 & 26,2 & 41,9 & 0,8213 \\
\hline Pozoamargo ........................... & 37,3 & 38,2 & 24,5 & 0,7760 \\
\hline El Provencio ...................... & 58,9 & 21,9 & 19,2 & 0,6258 \\
\hline Rada de Haro ..................... & 15,6 & 15,4 & 69,0 & 0,8716 \\
\hline San Clemente .................... & 36,5 & 35,4 & 28,1 & 0,7978 \\
\hline Santa María del Campo Rus ..... & 35,7 & 48,4 & 15,9 & 0,7457 \\
\hline Santa María de los Llanos ....... & 47,6 & 24,3 & 28,1 & 0,7267 \\
\hline 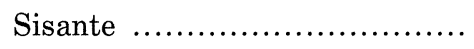 & 43,9 & 26,9 & 23,2 & 0,7633 \\
\hline Tresjuncos ......................... & 44,4 & 42,0 & 13,6 & 0,7355 \\
\hline Vara de Rey ......................... & 31,5 & 22,9 & 45,6 & 0,8078 \\
\hline Villaescusa de Haro .............. & 25,4 & 20,8 & 53,8 & 0,8228 \\
\hline Villamayor de Santiago .......... & 44,9 & 25,2 & 29,9 & 0,7402 \\
\hline Villar de la Encina ................ & 37,8 & 38,4 & 23,8 & 0,7449 \\
\hline Comarca ............................. & 40,0 & 30,2 & 29,8 & 0,7847 \\
\hline
\end{tabular}

Fuente: Catastro de Rústica. Padrones de propietarios (1988). Elaboración propia.

no e incluso algunos miembros de su familia realizan en el predio familiar.

Las actuales pequeñas explotaciones tienden a realizar cultivos mucho más intensivos y basan su rentabildad en el trabajo de los 
agricultores. En los pueblos comarcales donde la agricultura es más extensiva, como es el caso de Villar de la Encina, con predominio de la cebada y del girasol, pueden considerarse pequeñas propiedades aquellas que tienen menos de 25 ha. En Vara de Rey, sobre peores tierras y con algo de barbecho, con los mismos cultivos, este límite puede situarse entre las 30-35 ha. En Villamayor de Santiago, la actividad agrícola se diversifica hacia la vid, girasol, lentejas, trigo y cebada. Aquí el umbral podría estar entre las 20-25 ha. Donde es más intensivo, por la presencia de regadío, cultivando ajos y cebollas, y en secano viñedo, cereal y lentejas sería de unas 15-20 ha. Como ejemplo de esta última situación tendríamos a Las Pedroñeras, El Provencio, Casas de Fernando Alonso, etc.

Dado que lo dominante en la comarca son los cultivos de secano: cereal, girasol y algunos ajos, en los pueblos del norte, y cereal-leguminosas, ajos y viñedo en los del sur, creemos que el límite de la pequeña propiedad puede establecerse entre las 20-25 ha inclinándonos por las 25 en la Mancha Baja.

Este grupo de propietarios constituye el 96\% de los existentes en la comarca y les corresponde el $40 \%$ de la tierra catastrada. Debido a que todo el espacio es cultivable y a la presencia de viñedo, el porcentaje ( $45 \%$ ) de la base imponible es superior al de superficie poseída. La base media es de 6.267 pts. mientras que es bajísima la superficie con sólo 3,1 ha por propietario. En este estrato de propiedad, la base por hectárea es de 2.026 pts.

b) La delimitación de la gran propiedad.-Nuevamente consideraremos unos criterios cuantitativos, dado que la cantidad de tierra es, en sí misma, un elemento importante del que no debe prescindirse. En nuestra comarca, las propiedades mayores de 100, 250 y 500 ha suponen respectivamente el 41, 30 y $20 \%$ de la superficie. Si tenemos en cuenta la riqueza potencial de la tierra representada por la base imponible, nos encontramos que, en el intervalo de 100 a 249 ha, la superficie media es de 144,5 ha y la base media de 258.071 pts., mientras en el intervalo 250-499 son de 354 ha y 483.096 pts. respectivamente.

A partir de las 250.000 pts de base imponible, en 1988 podía considerarse la existencia de una gran propiedad en nuestra comarca. En estas circunstancias había 216 propietarios y el $32 \%$ de la base. Utilizar este criterio nos supondría incluir como gran propie- 
dad un finca de 41 ha de vinos en el término de El Provencio y excluir otra de 677 de erial en el de Vara de Rey.

La disponibilidad empresarial o «ingreso neto por explotación», es el criterio preferido por Mata (1987) para definir la gran propiedad, estableciéndolo en dos millones de pts. de 1979 para la campiña andaluza. Por efecto de la inflación, estos dos millones se han doblado en 1988. Los cuatro millones de ingresos netos se superaban en la Mancha Baja en las explotaciones entre 200 y 250 ha.

Intentado conjugar estos criterios, el de superficie, el de riqueza potencial de la tierra y el de ingreso neto, nos hemos inclinado por las 250 ha como un límite a partir del cual puede establecerse con cierta claridad que nos encontramos ante una gran propiedad en la Mancha Baja conquense. La base que les corresponde (22\%) es muy inferior a la superficie (30\%) debido a que el porcentaje de tierra no cultivada, en este tipo de propiedades, es muy alto. Esto se traduce en una base por hectárea de 1.322 pts. sensiblemente inferior a la de otros intervalos de propietarios. La superficie media es de 575 ha y la base de 760 .

En la mayor parte de las explotaciones agrarias con más de 200 ha, según el Censo de 1982, tenían una media de cuatro obreros fijos $\mathrm{y}$, en ellas, la mano de obra eventual solamente cobra importancia cuando hay viñas en la propiedad.

Estas propiedades generalmente constituyen grandes fincas o cotos redondos de origen diverso. Anteriores a la repoblación medieval pueden ser «Perona» (San Clemente), «Villar de Cantos» y «Villar de los Caballeros» (Vara de Rey). Otras proceden de la desamortización tanto eclesiástica como civil. Tal es el caso de las dehesas «Alcahozo» que fue de la Orden de Santiago, «La Poveda» y «El Rayo» (Belmonte), «Los Trenzones» (Los Hinojosos), el «Monte Moeda» (Las Mesas), «Los Albernagales» (Osa de la Vega), etc, que eran dehesas de los propios de dichos pueblos.

Otros aspectos muy importantes a señalar en el caso de las grandes propiedades, como indican Mata (1981) y Ocaña (1987), son: saber quiénes son los propietarios de la tierra, cuáles son los lazos de parentesco existentes entre ellos y su lugar de residencia. El conocimiento de estas circunstancias nos revelará la importancia de los grandes propietarios en esta comarca.

c) La propiedad media.-El intervalo de propietarios medios lo consideramos excesivamente amplio ya que abarca de las 25 a las

$$
-654-
$$


250 ha. Por ello, craemos conveniente desdoblarlo en dos subgrupos que denominamos bajo y alto.

El grupo de los medio-bajos sería aquel cuya superficie se encuentra entre las 25 y las 99 ha y corresponde al tipo de explotaciones agrícolas que no necesita emplear mano de obra asalariada fija. Es el propietario de la tierra quien aporta la fuerza de trabajo con la colaboración de familiares y ocasionalmente jornales eventuales, dependiendo de la superficie de viñedo que exista en la explotación, para poda y vendimia.

A estos propietarios medio-bajos les corresponde un porcentaje de superficie todavía inferior al de la base imponible, siendo el 18,9\% y el $21,4 \%$ respectivamente. La base media es de 91.732 pts. y la superficie media de 45,3 ha. La base por hectárea es de 2.026 pts. idéntica a la de la pequeña propiedad.

Los propietarios medio-altos son los que tienen entre 100 y 249 ha. En este tipo de explotaciones, el empleo de mano de obra fija es habitual: un obrero a tiempo completo, que es el tractorista, y dos a tiempo parcial además de los jornales eventuales para las labores en las viñas. En este grupo el porcentaje de base imponible $(11,3 \%)$ es igual al de superficie. La base por hectárea es de 1.786 pts. descendiendo a medida que aumenta el tamaño de la propiedad.

Estas propiedades medio-altas presentan unos rasgos que las asimilan más a las grandes que a las medio-bajas: empleo de obreros fijos, relación de parentesco con los grandes propietarios y base imponible media superior a las 250.000 pts. que, como ya hemos señalado, puede servir para empezar a caracterizar a la gran propiedad en esta comarca.

\section{Análisis de la propiedad por municipios}

En los distintos municipios de la comarca se produce una gran diversidad de situaciones en cuanto a la distribución de la propiedad de la tierra. Para conocer las características de cada municipio hemos partido de la clasificación de la propiedad en los tres grandes grupos de pequeños medianos y grandes. Cada uno de ellos lo designamos con los números 1,2 y 3 y las letras a, b y c.

$$
-655-
$$




\section{CuAdro III}

PRINCIPALES TIPOS DE PROPIEDAD DE LA TIERRA

\begin{tabular}{|c|c|c|c|}
\hline & $\begin{array}{l}\text { Pequeña } \\
\text { (a) }\end{array}$ & $\begin{array}{l}\text { Mediana } \\
\quad \text { (b) }\end{array}$ & $\begin{array}{l}\text { Grande } \\
\text { (c) }\end{array}$ \\
\hline $\begin{array}{l}\text { Pequeña } \\
\text { (1) }\end{array}$ & $\begin{array}{l}\text { Casas de } \\
\quad \text { Fdo. Alonso } \\
\text { Casas de Guijarro } \\
\text { Casas de los Pinos } \\
\text { El Provencio }\end{array}$ & $\begin{array}{l}\text { Belmonte } \\
\text { Casas de Haro } \\
\text { Las Mesas } \\
\text { Mota del Cuervo } \\
\text { San Clemente } \\
\text { Tresjuncos }\end{array}$ & $\begin{array}{l}\text { Sta. M. }{ }^{a} \text { de los Llanos } \\
\text { Villamayor de Santiago } \\
\text { Sisante }\end{array}$ \\
\hline $\begin{array}{l}\text { Mediana } \\
\text { (2) }\end{array}$ & $\begin{array}{l}\text { Alberca de Záncara } \\
\text { Casas de Benítez } \\
\text { Sta. M. }{ }^{a} \text { del Campo } \\
\text { Rus } \\
\text { Pozoamargo } \\
\text { Villar de la Encina }\end{array}$ & $\begin{array}{l}\text { Fuentelespino de Haro } \\
\text { Monreal del Llano } \\
\text { Osa de la Vega }\end{array}$ & \\
\hline $\begin{array}{l}\text { Grande } \\
\text { (3) }\end{array}$ & $\begin{array}{l}\text { Carrascosa de Haro } \\
\text { Los Hinojosos } \\
\text { Las Pedroñeras } \\
\text { Vara de Rey }\end{array}$ & $\begin{array}{l}\text { Hontanaya } \\
\text { El Pedernoso }\end{array}$ & $\begin{array}{l}\text { Rada de Haro } \\
\text { Villaescusa de Haro }\end{array}$ \\
\hline
\end{tabular}

La pequeña es dominante en casi la mitad de los municipios de la comarca. En ellos se encuentra el $54 \%$ de la superficie catastrada. Como puede observarse en el mapa adjunto, esto sucede fundamentalmente en los pueblos del sur de la comarca en los que es más importante el cultivo de la vid.

La propiedad media cobra importancia en ocho municipios a los que corresponde el $18 \%$ de la superficie catastrada. En ellos, el 48\% de la tierra se localiza en este tipo de propiedades siendo muy destacable también la pequeña. En general predominan los cultivos herbáceos aunque, en dos de ellos (Casas de Benítez y Pozoamargo), es más importante el papel del viñedo.

La grande es claramente dominante en los ocho municipios restantes a los que corresponde el $28 \%$ del suelo comarcal. En ellos, casi el $50 \%$ de la tierra se encuentra en este grupo de propiedades. Las

$$
-656-
$$


CuAdro IV

CARACTERÍSTICAS ESPACIALES DE LA PROPIEDAD RÚSTICA

\begin{tabular}{lrccccc}
\hline $\begin{array}{c}\text { Propiedad } \\
\text { dominante }\end{array}$ & $\begin{array}{c}\text { Municipios } \\
\text { N. }\end{array}$ & $\begin{array}{c}\text { Superficie } \\
\%\end{array}$ & \multicolumn{3}{c}{ Porcentaje de tierra en propiedades } \\
Pequeñas & Medianas & Grandes & Total \\
\hline Pequeña .... & 13 & 53,7 & 50,2 & 28,5 & 21,2 & 100,0 \\
Mediana .... & 8 & 18,0 & 35,2 & 47,7 & 17,1 & 100,0 \\
Grande ..... & 8 & 28,3 & 26,1 & 26,7 & 48,2 & 100,0 \\
Total ....... & 29 & 100,0 & 100,0 & 100,0 & 100,0 & 100,0 \\
\hline
\end{tabular}

Fuente: Catastro de Rústica. Padrones de propietarios (1988). Elaboración propia.

pequeñas y medianas se reparten casi por mitad el resto del terrazgo. En estos términos la mayor parte del espacio cultivado se dedica a cereales y girasol si exceptuamos Las Pedroñeras, donde el viñedo es importante, sobre todo en las medianas y pequeñas explotaciones.

\section{Municipios con predominio de la pequeña propiedad}

1a) La pequeña propiedad es claramente dominante en cuatro términos: Casas de Fernando Alonso, Casas de Guijarro, Casas de los Pinos y El Provencio donde supone el 66\% del suelo catastrado. Casas de Fdo. Alonso y Casas de Guijarro son dos pequeños municipios en los que no hay grandes propietarios. En el primero de ellos, por incitativa del IRYDA, se han puesto en regadío 645 ha. en la zona de «El Simarro» beneficiando a muchos pequeños propietarios y también a algunos medianos. En los otros dos, junto a la numerosa pequeña propiedad hay que destacar la existencia de algunos medianos y grandes propietarios, como es el caso de Jareño López de Haro, descendiente de uno de los mayores contribuyentes de la provincia de Cuenca en el siglo pasado, y de Jiménez de Córdoba Acucio que con 756 ha, la mayor parte de viñas, es uno de los propietarios con mayor base imponible en el conjunto comarcal. En Casas de los Pinos destacan las propiedades de la familia Ciller de Albacete, con unas 1800 ha., de las cuales casi 1000 constituyen la finca «Casa del Angel», explotada por una sociedad anónima del mismo nombre, en la que se han instalado diez pivotes y riego por cobertura total (Gesteiro, 1992).

$$
-657-
$$




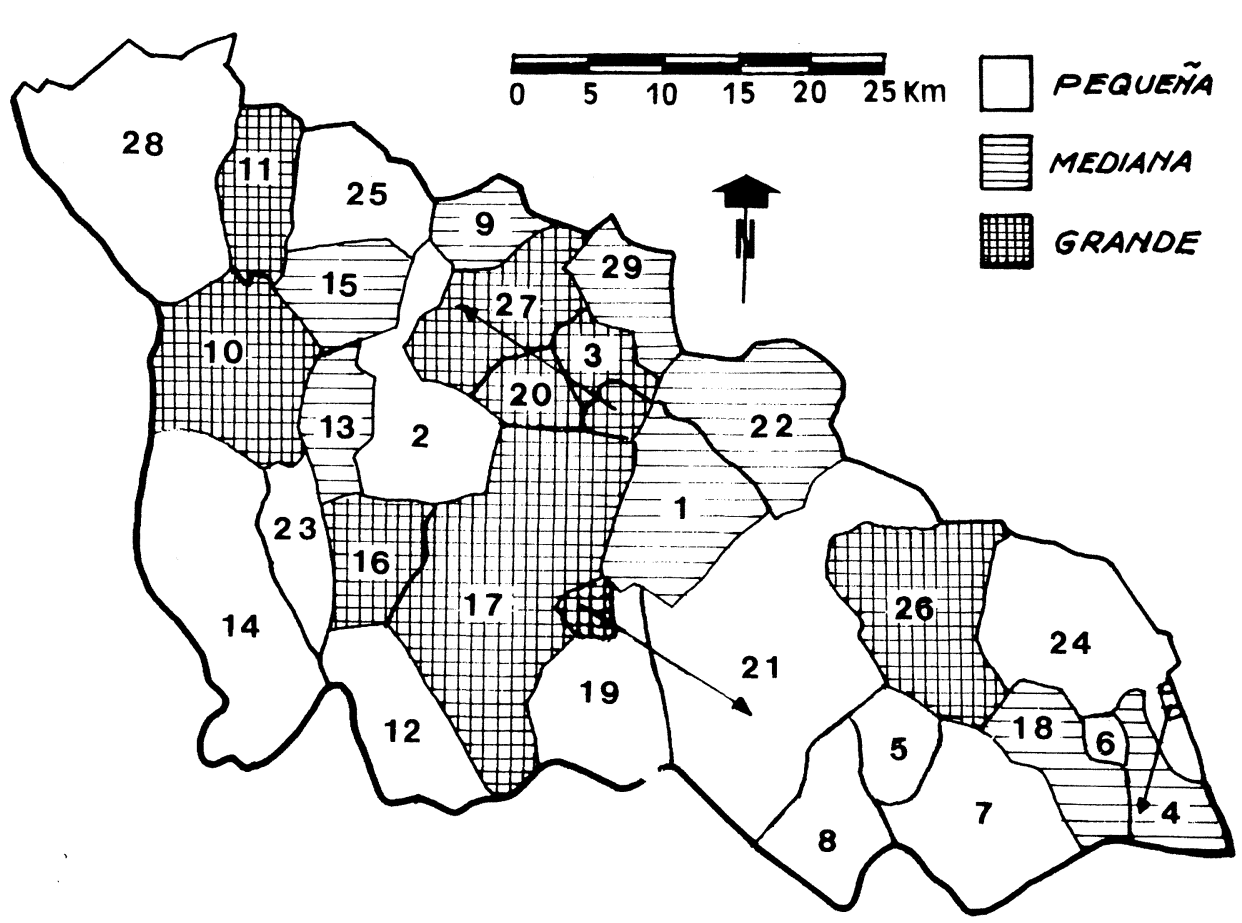

Tipo de propiedad por municipios:

1. La Alberca de Záncara

2. Belmonte

3. Carrascosa de haro

4. Casas de Benítez

5. Casas de Fernando Alonso

6. Casas de Guijarro

7. Casas de Haro

8. Casas de los Pinos

9. Fuentelespino de Haro

10. Los Hinojosos

11. Hontanaya

12. Las Mesas

13. Monreal del LLano

14. Mota del Cuervo

15. Osa de la Vega
16. El Pedernoso

17. Las Pedroñeras

18. Pozoamargo

19. El Provencio

20. Rada de Haro

21. San Clemente

22. Santa María del Campo Rus

23. Santa María de los Llanos

24. Sisante

25. Tresjuncos

26. Vara de Rey

27. Villaescusa de Haro

28. Villamayor de Santiago

29. Villar de la Encina

1b) Pequeña-mediana propiedad se localiza en siete municipios, con amplios contrastes y situaciones muy diversas, aunque predominan los del sur de la comarca en los que los cultivos leñosos, funda- 
mentalmente viñas, ocupan una parte destacada del terrazgo. El que la mayor parte de la superficie (43\%) se encuentre en las pequeñas propiedades no significa que no existan en ellos algunas grandes cuyas circunstancias pasamos a analizar.

En San Clemente nos encontramos con 1.475 ha., sobre todo pinares, que constituyen el único gran patrimonio de propiedad municipal en este área de estudio. En dicho municipio hay varios grandes propietarios residentes en Madrid y emparentados entre sí. Este es el caso de Melgarejo Martínez del Peral, marqués de Melgarejo (1.776 ha.) y de Martínez del Peral Fortón, marqués de Valdeguerrero con 1733 ha. en la finca «Perona», en la que se regaban 864 ha con pivots, a las que habría que añadir 1.383 de otros miembros de la familia.

Algunos propietarios medios son familiares de otros grandes propietarios de localidades vecinas, como es el caso de los Jareño López de Haro en El Provencio y Briz Risueño y Risueño Cuadra en Casas de Fdo. Alonso.

El marqués de Melgarejo es también un gran propietario en Belmonte con 1.243 ha. entre las que están las antiguas dehesas de propios «El Rayo» y «La Poveda». En este último municipio debe citarse también la existencia de propietarios de otra naturaleza jurídica. La Fundación Moreno Bahillo constituida en parte con los bienes de Bahillo, un político del siglo xIx, comprador de tierras desamortizadas. El hospital de San Andrés, fundación bajo medieval de Juan Pacheco, marqués de Villena (Franco, 1987), con tierras en Belmonte y otros pueblos limitrofes. Una S.A.T. llamada «Cohersa» con fincas y ganado en ésta y otras localidades contiguas. Algunos medianos propietarios de Belmonte también lo son en los pueblos vecinos de Osa de la Vega, como es el caso de los Ruiz Pinedo o incluso grandes como Cuartero Pascual (Sociedad ECUSA), en Las Mesas.

1c) Tres son los municipios en los que, predominando la pequeña propiedad (45\%), la grande supera a la mediana. Sisante, Villamayor de Santiago y Santa María de los Llanos se caracterizan por los cultivos leñosos: vid y olivar, aunque en menor medida que los herbáceos en los dos primeros, y dominantes el viñedo y los ajos en el tercero.

En Santa María de los Llanos destacan los hermanos Perona Ojero (370 ha.), el Ayuntamiento (425) y sobre todo la finca «Buenavis-

$$
-659-
$$


ta» (426), propiedad del marqués de Melgarejo, en la que se han realizado importantes inversiones para su puesta en regadío.

En Villamayor de Santiago varios miembros de la familia Lodares, una de las más ricas de la comarca, residentes en Madrid en su mayor parte, figuran entre los grandes propietarios: Lodares Lodares 1.413 ha. y Palomino Lodares 1.117. Así como los de otras familias relacionadas entre sí: Durán Saavedra (333 ha.), Saavedra García Pando (111), García Pando Gómez (628), etc.

En Sisante hay siete grandes propietarios de entre los que podemos destacar nuevamente a una Lodares, Concepción Lodares Alfaro (681 ha.) y a Juan J. Berruga de Arce (789) y por último, a la Sociedad de Explotaciones Cinegéticas (539), etc.

\section{Municipios con predominio de la mediana propiedad}

2b) Tres son los términos en los que la mediana propiedad supera el $50 \%$ de la superficie local: Fuentelespino de Haro, Monreal del Llano y Osa de la Vega.

El mayor propietario de Fuentelespino de Haro es el Ayuntamiento con 444 ha de eriales y pinos de relativamente reciente plantación. La mayor parte de la tierra lo es de propietarios medios o mediobajos que no superan las 200 ha. Uno de ellos es Consuelo González Lodares, gran propietaria en la vecina localidad de Villaescusa de Haro.

Monreal del Llano es un pequeño municipio en el que el 54,3\% de la superficie está en las medianas propiedades. Seis miembros de la familia Garnica Zapatero, residentes en Madrid, tienen 694 ha., y varios Lodares llegan a las 248. Así mismo merecen destacarse las 347 ha. que Melgarejo Martínez del Peral posee en este pueblo, del que es mayor hacendado.

Osa de la Vega es el término en el que la propiedad media ocupa un mayor porcentaje de tierras (60\%), pero, como en los casos anteriores, controlada por unas pocas familias, tal es el caso de los Belinchón, Carrasco, Buendía, Ruiz Pinedo, etc. con relaciones de parentesco entre ellas. Además hay grandes propietarios de otros pueblos que en éste son medianos, como sucede con los Melgarejo, Lodares, etc. 
2a) En este grupo nos encontramos con cinco municipios. En dos de ellos, Pozoamargo y Villar de la Encina, mediana y pequeña propiedad tienen prácticamente los mismos porcentajes de tierra. En el primero dominan el cereal y el viñedo y en el segundo el cereal y el girasol. En Pozoamargo, tres miembros de una misma familia, los Galiano Martínez Medinilla son propietarios del $21 \%$ de la superficie. En Villar de la Encina, siete propietarios medios, emparentados entre ellos, controlaban el $28 \%$ de la tierra.

En las otras tres localidades es claramente superior la mediana propiedad, destacando la media-alta en Casas de Benítez. En este último término dominan el viñedo y los cereales, mientras en La Alberca de Záncara y en Santa María del Campo Rus lo hacen el cereal y el girasol. Aunque en estos términos la gran propiedad es poco significativa, hay unas pocas familias de propietarios medio-grandes relacionadosentre sí y duenos a su vez en otros pueblos comarcales de importantes patrimonios. En La Alberca destacan los Pinuaga, Mogorrón, Garcés, Serrano, Perea, etc. En Casas de Benítez los De la Torre Gosalvez, Llopis, Manresa, Bercuga, etc. y en Santa María del Campo los Pinuaga, Perona, Sanado, Martínez del Peral, etc.

\section{Municipios con predominio de la gran propiedad}

3c) La gran propiedad supone el $61 \%$ de la tierra en los municipios de Rada de Haro y Villaescusa de Haro en los cuales se localiza la mayor parte de una antigua Encomienda de la Orden de Santiago, desamortizada en la época de Mendizábal (González Marzo, 1985). Sus tierras aparecen repartidas entre los hermanos del torero Chicuelo II (641 ha.), Álvarez Mendizábal Vega (653) y Pastor Carbanell (415). Además, y como es tan frecuente en la comarca, existen otros grandes propietarios que lo son en éstos y otros municipios anteriormente citados. Destaquemos las 1.097 ha. de Consuelo Lodares y las 166 de Gabrial Lodares. Carlos Girón Portillo y Da Carmen Portillo Astrana tienen respectivamente 814 y 582 ha. Y el tantas veces citado Melgarejo Martínez del Peral tiene 794.

3b) Con predominio de la grande y mediana propiedad nos encontramos a Hontanaya y El Pedernoso. En Hontanaya los cultivos fundamentales son el cereal y el girasol, mientras montes y eriales

$$
-661-
$$


ocupan las laderas de la mesozoica sierra de Almenara. Entre los grandes destacan tres hermanos Palomino Lodares (1.275 ha.) y tres Pinedo Pinedo (472), así como José J. Lodares (344) y Enrique Contreras (508).

El Pedernoso es un municipio de la llanura que presenta una gran diversidad de cultivos, así como 645 ha de regadío instalado por el IRYDA para pequeños y medianos agricultores, cuya gestión lleva la S.A.T. «Abuela Santa Ana». El mayor propietario es el Ayuntamiento con 513 ha. de eriales. Entre los medianos y grandes propietarios destacan los hermanos María Angeles y Carlos Garnica Zapatero con 378 ha., 60 de ellas en la zona de regadío, así como los Jareño-Perona-López de Haro con 891. Todos ellos son parientes de grandes terratenientes en otros municipios y ellos son, a su vez, poseedores de tierras en otros términos.

3a) Cuatro son los municipios en los que predominando la gran propiedad, $45 \%$ de la superficie, la pequeña supone un porcentaje muy semejante, $41,5 \%$, dándose así una dualidad muy acusada. Cada uno de estos términos presenta unas condiciones específicas que los diferencian de los restantes.

Las Pedroñeras es un gran concejo extendido de norte a sur con más de veintidós mil hectáreas. Los pequeños propietarios, a los que pertenece el $32 \%$ de la superficie municipal, hacen que el viñedo y los ajos sean cultivos muy frecuentes especialmente en la llanura manchega del sur comarcal. La gran propiedad es importantísima, pues hay 15 titulares que superan las $25 \mathrm{G}$ ha. y les corresponde el $42 \%$ de la superficie. El relieve favorable, la buena calidad de los suelos y la presencia de viñedo y regadío en algunas propiedades, hacen que sean 25 los titulares que superan las 250.000 pts. de base imponible. Entre las grandes fincas destacamos «La Veguilla» con casi 2.000 ha., antigua propiedad de Salvador Amorós Cerdán y hoy de una sociedad que lleva el nombre de la finca. Su explotación está siendo objeto de profundas transformaciones como lo demuestra el hecho de que en los pasados 1988-89 se hayan instalado cinco pivotes y puesto en riego unas 200 ha. otros grandes propietarios son los ya citados Alvarez Mendizábal Vega (1.384 ha.) y Jareño López de Haro (936), ambos fallecidos.

Carrascosa de Haro, perteneciente a la antigua jurisdicción de Haro, comparte con Rada y Villaescusa la antigua Encomienda de la 
Orden de Santiago que en este municipio pertenece a los hermanos de Chicuelo II. otro gran propietario es J. Fco. Pinuaga (703 ha.) quien, en los últimos años, ha realizado una importante compra de tierras en Belmonte.

En Vara de Rey, donde el 45,6 \% del suelo se concentra en cinco grandes propiedades, destacan las fincas «Villar de Cantos», «Villar de los Caballeros» y «El Monte» en las que las familias Melgarejo y Martínez del Peral reúnen 4.000 ha. Es un término dominado por los cultivos extensivos con un gran porcentaje de la superficie, especialmente en las grandes propiedades, a erial y barbecho y en el que lo más importante es el cereal seguido del girasol.

Los Hinojosos presenta como característica especial el hecho de que la mitad occidental está dominada por grandes fincas, mientras en la oriental la propiedad está extraordinariamente fragmentada. La primera fue jurisdicción de la Orden de Santiago y el pueblo se llamaba El Hinojoso de la Orden, la segunda pertenecía al Marquesado de Villena y recibía el nombre de El Hinojoso del Marquesado. La fusión de ambos se produjo en el siglo xIX. Los Lodares, que ya eran mayores hacendados en el siglo xvIII y fueron importantes compradores en la desamortización, son los grandes propietarios de este municipio. Ramón y José Lodares suman casi 2.000 ha. Tres miembros de la familia Palomino Lodares, ya citados como grandes propietarios en Hontanaya, reunen 301, Lodares Alfaro 190, Lodares Quintana 104 ha., etc. Asi mismo hay otros importantes propietarios como lo son José Fernández Fontecha (1.041 ha.) y M. ${ }^{\mathrm{a}}$ Gracia Salva Font (639). Por último, citaremos la sociedad «Cueva del Granero» que, entre Los Hinojosos y el vecino Villamayor de Santiago, tiene unas 1000 ha. en las que se ha realizado una importante ampliación del espacio cultivado primero con cereales y más recientemente con viñas que la misma sociedad elabora y comercializa, entre otras, con la marca «Cueva del Granero».

\section{Conclusiones}

La estructura de la propiedad de la tierra en la Mancha Baja se asemeja bastante a las hipótesis que Mata Olmo (1988) plantea para el conjunto de Castilla-La Mancha.

$$
-663-
$$


- Existe un fuerte contraste entre pequeña y gran propiedad. El grupo de los pequeños es numerosísimo, generalmente con buenas tierras cuya explotación ha dado lugar a un importante cambio en la agricultura comarcal. Por otra parte, muy pocos grandes propietarios, generalmente con tierras de peor calidad y con una explotación agropecuaria de carácter extensivo. Algunas de estas grandes fincas se están modernizando en los últimos años, ampliando la superficie cultivada, introduciendo girasol, viñedo, regadíos y convirtiéndose en sociedades anónimas.

- Las grandes propiedades no se circunscriben a un sólo municipio sino que frecuentemente, una persona o un grupo familiar, tiene grandes fincas en varios pueblos de la comarca e incluso en las provincias limitrofes.

- Existe un fuerte control de la tierra por parte de unas oligarquías locales, antano hidalgos, caballeros o labradores ricos, algunos de los cuales se ennoblecieron posteriormente y cuyos patrimonios se ampliaron después de la desamortización del siglo XIX.

- Estas oligarquías, de origen local o comarcal, unidas entre sí por lazos de parentesco, acaban siendo absentistas al fijar su residencia fuera del espacio comarcal, especialmente en Madrid.

- La presencia de las propiedades públicas es muy reducida una vez desaparecidos los patrimonios municipales después de la desamortización.

\section{BIBLIOGRAFIA}

Elías Castillo, F. y Ruiz Beltrán, L. (1981): Estudio agroclimático de la región Castilla-La Mancha. Junta de Comunidades de Castilla-La Mancha. Madrid, 247 págs.

Franco Silva, A. (1987): «Los testamentos de Juan Pacheco (1470-1472)». Congreso de Historia del Señorío de Villena. CSIC.Instituto de Estudios Albacetenses, págs. 157174.

Gesteiro Araujo ,M. (1990): Geografía Agraria de la Mancha Baja (Cuenca). Tesis doctoral. Universidad Autónoma de Madrid, 1553 págs.

- (1992): «E1 riego pivotante y la transformación del paisaje agrario en la mancha conquense». Estudios Geográficos , n- 207, págs. 291-306.

- (1994): «Grandes propietarios en la Mancha Baja (Cuenca)». VII Coloquio de Geografía Rural. Universidad de Córdoba, págs. 47-52.

GonzÁlez MARZo, F. (1985): La desamortización de la tierra eclesiástica en la provincia de Cuenca. Excma. Diputación Provincial de Cuenca. 162 págs.

- (1988): «Los beneficiarios del proceso desamortizador en la provincia de Cuenca (1836-45)». I Congreso de Historia de Castilla-La Mancha. Tomo IX, págs. 8592.

$$
-664-
$$


Junta de Comunidades de Castilla-La mancha. (1985): Sintesis hidrogeológica de Castilla-La Mancha. Madrid, IGME, Colección Informes n.- 97, 107 págs.

López Ontiveros, A. (1971): «Notas sobre el catastro actual como fuente geográfica». Estudios Geográficos , n- 122, págs. 119-143.

Mata Olmo, R. (1981): «Notas sobre la situación actual de la gran propiedad en la Campiña gienense». Estudios Geográficos, n.- 163, págs. 139-165.

- (1987): Pequeña y gran propiedad en la depresión del Guadalquivir. Madrid, Ministerio de Agricultura, Pesca y Alimentación. 2 Tomos, 334 y 447 págs.

- (1988): «La distribución de la propiedad y de la explotación de la tierra en CastillaLa Mancha. Aspectos de la situación actual y su dinámica reciente». II Reunión de Estudios Regionales de Castilla-La Mancha. Ciudad Real. Excma. Diputación Provincial. Tomo II, págs. 165-206.

OCAÑa OCAÑa, M. ${ }^{a}$ C. (1987): «Hacia una tipificación de la gran propiedad andaluza» Estructura y regimenes de tenencia de la tierra en España. Madrid. Ministerio de Agricultura, Pesca y Alimentación, págs. 335-350. 